\title{
REVIEW \\ Effect of Gibberellin Biosynthesis Inhibitor on Prevention of Precocious Bolting and Flowering in Japanese Radish (Raphanus sativus L.)
}

\author{
Takaaki NISHIJIMA ${ }^{1 *}$ \\ Department of Applied Physiology, National Research Institute of Vegetables, Ornamental Plants and \\ Tea (Ano, Mie 514-2392, Japan)
}

\begin{abstract}
Prevention of precocious bolting, i.e. stem elongation accompanied by flowering, in Japanese radish (Raphanus sativus L.) was attempted using a foliar spray of uniconazole, a gibberellin biosynthesis inhibitor. At first, appropriate conditions for the prevention of precocious bolting, such as uniconazole concentration, extent of vernalization and floral stage were investigated using an incubator. Higher uniconazole concentration ( $\geqq 17 \mu \mathrm{M}$ ) and shorter duration of vernalization were found to be desirable. For effective retardation of bolting and flowering, uniconazole should be applied before floral evocation. Based on these results, uniconazole was applied to cv. 'Taibyo-sobutori' and cv. 'Oshin' during winter and spring cultivation. Bolting and flowering were delayed up to 10 and 6 days, respectively, when the uniconazole $(17 \mu \mathrm{M})$ treatment was administered before floral evocation.
\end{abstract}

Discipline: Horticulture

Additional key words: growth retardant, foliar spray, low temperature, long day

\section{Introduction}

Japanese radish (Raphanus sativus L.) consists of several groups of cultivars differing in their flowering properties. Since these groups, i.e. autumn, spring and summer cultivar groups, were well suited to autumn, spring and summer cultivation, respectively, year-round cultivation system had been applied for hundreds of years ${ }^{9}$. However, due to the consumer demand for highquality products, the farmers have tended to use highquality autumn cultivars in winter and spring cultivation. This has resulted in precocious bolting and flowering by low temperature and subsequent long daylength ${ }^{3}$. Breeding of slow-bolting cultivars and cultivation using film mulching, plastic tunnels or plastic houses enabled to alleviate this problem ${ }^{3,10}$. However, excessive early planting aimed at increasing the product price, and unusual weather conditions sometimes cause precocious bolting and flowering ${ }^{1}$.

Previous studies suggested that gibberellin was involved in floral induction in Japanese radish exposed to long daylength ${ }^{6,7}$ and that the reduction of the endogenous gibberellin concentration delayed floral evocation and bolting 5 . In winter and spring cultivation, it is likely that plants are cold-induced during the early growth period and then floral induction and evocation occur under long-day conditions during the mid- to later growth period. Thus it is predicted that the reduction of the endogenous gibberellin concentration under long-day conditions during the mid- to later growth period could successfully delay precocious bolting and flowering.

In this report, the effect of uniconazole, a gibberellin biosynthesis inhibitor, on bolting and flowering in Japanese radish in winter and spring cultivation was investigated. Based on the results obtained, a possible procedure for chemical control of precocious bolting was examined.

The experiment consisted of two phases. The first phase of the experiment was conducted in an incubator to identify a method for effective treatment based on the physiological status of the plants. In the second phase,

\footnotetext{
Present address:

${ }^{1}$ Department of Genetics and Physiology, National Institute of Floricultural Science (Tsukuba, Ibaraki 305-8519, Japan) *Corresponding author: fax +81-29-838-6841; e-mail takaaki@affrc.go.jp

Received 2 December 2002; accepted 4 March 2003.
} 
the method for treatment developed in the first phase was applied to winter and spring cultivation using film mulching or plastic tunnels.

\section{Methods for cultivation and uniconazole treatment}

\section{Identification of a method for effective treatment using uniconazole \\ Raphanus sativus cv. 'Taibyo-sobutori' (Takii Seed} Co., Japan) was used. Seeds were planted in a 1/5000a Wagner pot filled with a mixture of commercial horticultural soil (Kureha Chemical Co., Japan) and sand (1:1). The plants were grown for 10 days in an incubator with illumination from metal halide lamps $\left(470 \mu \mathrm{mol} \cdot \mathrm{m}^{-2} \cdot \mathrm{s}^{-1}\right)$ under $8 \mathrm{~h}$ daylength. Chilling treatment was applied at $5^{\circ} \mathrm{C}$ with illumination from fluorescent lamps (14 $\mu \mathrm{mol} \cdot \mathrm{m}^{-2} \cdot \mathrm{s}^{-1}$ ) under $8 \mathrm{~h}$ daylength. The plants were then grown again in the incubator described above with the daylength extended to $16 \mathrm{~h}$ with incandescent lamps (10 $\mu \mathrm{mol} \cdot \mathrm{m}^{-2} \cdot \mathrm{s}^{-1}$ ) from the end of the main light period. Three plants were grown in a pot, and 12 plants were used per treatment.

Aqueous uniconazole (Sumiseven-P, Sumitomo Chemical Co., Japan) solution was sprayed onto the whole shoot at the end of, or 10 days after the chilling treatment. After the uniconazole treatment, shoot apexes of 10 plants were collected and the floral stage was examined with a microscope. Plants were harvested at the time of flower opening for the investigation of flowering. Plants without flower opening were harvested 80 days after the end of the chilling treatment and the floral stage was investigated by observing the shoot apex with a microscope. Data were statistically analyzed by Tukey's test.

\section{Effect of uniconazole treatment in winter and spring cultivation}

Cultivars 'Taibyo-sobutori' (moderately slow-bolting cultivar, Takii Seed Co., Japan) and cv. 'Oshin' (slow-bolting cultivar, Takii Seed Co., Japan) were used. The experiment was conducted from February to July, 1996 in the experimental field of the National Research Institute of Vegetables, Ornamental Plants and Tea (Ano, Mie, Japan). The procedure for cultivation is summarized in Fig. 1. Fertilization and planting distances were set up following a standard cultivation method ${ }^{3}$. Two protection methods were used for cultivation. The first consisted of film mulching with a polyethylene film $(0.02$ $\mathrm{mm}$ in thickness), and the second of film mulching in combination with a plastic tunnel $(60 \mathrm{~cm}$ in height and $120 \mathrm{~cm}$ in width) made of polyvinyl chloride film (0.05 $\mathrm{mm}$ in thickness). The tunnel was completely closed up

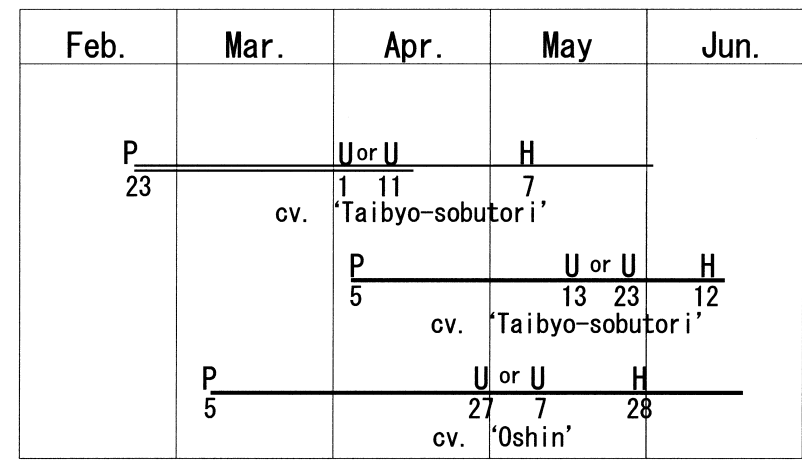

Fig. 1 Scheme of cultivation and chemical treatment for $\boldsymbol{R}$. sativus cv. 'Taibyo-sobutori' and cv. 'Oshin'

Letters indicate planting $(\mathrm{P})$, uniconazole treatment (U) and harvest $(\mathrm{H})$. Numbers below the letters indicate the day. Single line represents growth in the open field with film mulching. Double line represents growth in plastic tunnel with film mulching. Percentage of plants that reached the dome-shaped stage of flowering: $8 \%$ on April 1 and $58 \%$ on April 11 in cv. 'Taibyo-sobutori' planted on February 23; $92 \%$ on May 13 and $100 \%$ on May 23 in cv. 'Taibyo-sobutori' planted on April 5; 58\% on April 27 and $100 \%$ on May 7 in cv. 'Oshin' planted on March 5.

to the 6 leaf stage, then ventilated and completely removed according to the standard cultivation method. Uniconazole ( $17 \mu \mathrm{M}$, equivalent to $5 \mathrm{mg} / \mathrm{L}$ ) was sprayed onto the whole shoot at the 7-13 leaf stage or 10 days after this stage. Bolting corresponded to the time when the epicotyl length reached $5 \mathrm{~cm}$. Forty plants were used per treatment. Half of the plants were harvested when about half of the control plants without uniconazole treatment bolted. The harvested plants were used for investigations of the growth of shoot and taproot. The other half of the plants was retained in the field until most of the control plants flowered. Statistical analysis was conducted as described above.

\section{Conditions necessary for effective retardation of bolting and flowering by uniconazole}

All of the plants which were subjected to the cold treatment and then grown in an incubator under long daylength bolted and flowered if they were not treated with uniconazole (Table 1). Days to bolting and flowering (Fig. 2) and leaf number (Fig. 3) increased with decreasing chilling duration. The plants were at the vegetative stage at the end of the chilling treatment. However, most of the plants reached or passed the dome-shaped stage 10 days after the chilling treatment. Ten, 9 and 7 out of 10 plants reached or passed this stage after 25,20 and 15 
Table 1. Effects of chilling duration, time and concentration of uniconazole treatment on bolting and flowering in $R$. sativus cv. 'Taibyo-sobutori'

\begin{tabular}{|c|c|c|c|c|}
\hline \multirow{2}{*}{$\begin{array}{l}\text { Chilling } \\
\text { treatment } \\
\text { (day) }\end{array}$} & \multicolumn{2}{|c|}{ Uniconazole treatment } & \multicolumn{2}{|c|}{ Percentage of plants } \\
\hline & $\begin{array}{l}\text { Treatment time } \\
(\mathrm{DAC})^{\mathrm{a})}\end{array}$ & $\begin{array}{l}\text { Concentration } \\
\qquad(\mu \mathrm{M})\end{array}$ & Bolting & $\begin{array}{l}\text { Flower } \\
\text { opening }\end{array}$ \\
\hline \multirow[t]{7}{*}{15} & $\mathrm{NT}^{\mathrm{b})}$ & - & 100 & 100 \\
\hline & 0 & 3.5 & 100 & 100 \\
\hline & & 17 & 75 & 75 \\
\hline & & 35 & 75 & 50 \\
\hline & 10 & 3.5 & 92 & 92 \\
\hline & & 17 & 100 & 92 \\
\hline & & 35 & 100 & 83 \\
\hline \multirow[t]{7}{*}{20} & NT & - & 100 & 100 \\
\hline & 0 & 3.5 & 100 & 100 \\
\hline & & 17 & 92 & 83 \\
\hline & & 35 & 83 & 58 \\
\hline & 10 & 3.5 & 100 & 100 \\
\hline & & 17 & 100 & 100 \\
\hline & & 35 & 83 & 83 \\
\hline \multirow[t]{7}{*}{25} & NT & - & 100 & 100 \\
\hline & 0 & 3.5 & 100 & 100 \\
\hline & & 17 & 100 & 100 \\
\hline & & 35 & 100 & 100 \\
\hline & 10 & 3.5 & 100 & 100 \\
\hline & & 17 & 100 & 100 \\
\hline & & 35 & 100 & 100 \\
\hline
\end{tabular}

a): Days after chilling treatment.

b): Not treated.

days of chilling treatment, respectively.

When uniconazole was applied at the end of the chilling treatment, all the plants subjected to 25 days of chilling treatment bolted (Table 1), whereas several plants subjected to 20 or 15 days of chilling treatment did not bolt. Days to bolting and leaf number could be increased by uniconazole treatment, regardless of the chilling duration. Flower stem length of the uniconazoletreated plants was $1 / 2$ to $1 / 3$ that of the untreated ones at the time of flower opening (data not shown). The lowest uniconazole concentration which significantly retarded bolting during all the periods of the chilling treatment was $17 \mu \mathrm{M}$. Shortening of the period of the chilling treatment enhanced the effect of uniconazole, i.e., the extent of increase in days to bolting and leaf number.

Uniconazole applied 10 days after the chilling treatment also retarded bolting and flowering. However, the extent of retardation was smaller than when uniconazole was applied at the end of the chilling treatment, presumably because in a substantial number of plants floral evocation occurred up to 10 days after the chilling treatment.

From these results, it can be concluded that unicona-

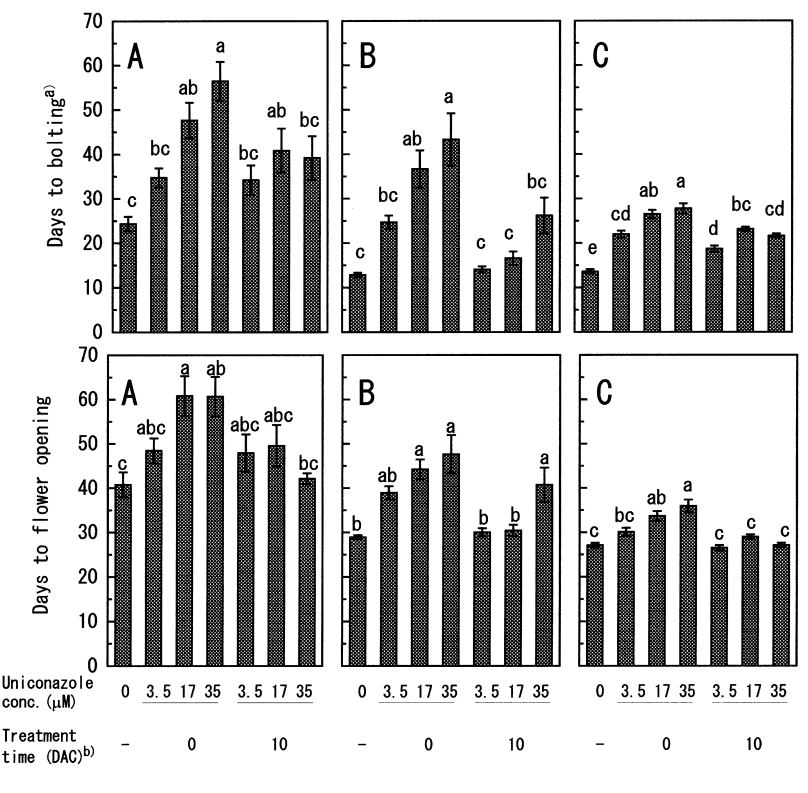

Fig. 2. Effects of chilling duration, time of uniconazole treatment and uniconazole concentration on the days to bolting and flower opening in $R$. sativus $\mathrm{cv}$. 'Taibyo-sobutori'

The plants were grown for 80 days under long daylength after 15 (A), 20 (B) and 25 (C) days of chilling treatment. Vertical bars indicate \pm SE. Columns with the same letter are not significantly different at $5 \%$ level. a): Days to bolting refers to the period from the end of the chilling treatment to the time when the stem length reached $7 \mathrm{~mm}$. b): Days after chilling treatment.

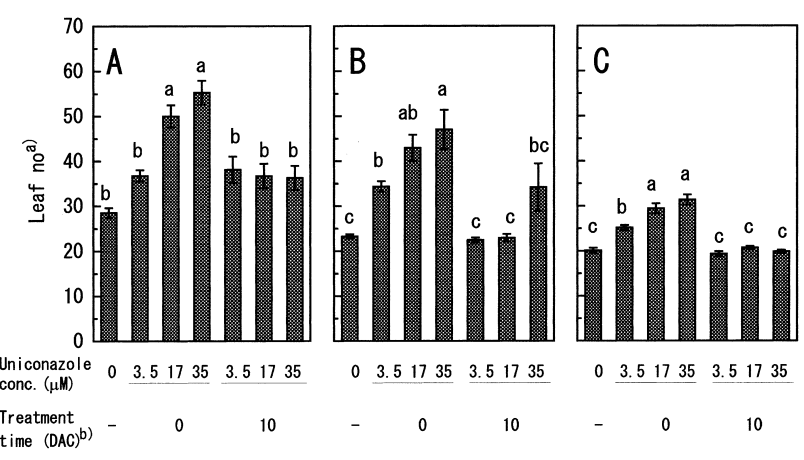

Fig. 3. Effects of chilling duration, time of uniconazole treatment and uniconazole concentration on leaf number in $R$. sativus cv. 'Taibyo-sobutori'

The plants were grown for 80 days under long daylength after 15 (A), 20 (B) and 25 (C) days of chilling treatment. Vertical bars indicate \pm SE. Columns with the same letter are not significantly different at $5 \%$ level. a): Data at the end of growth for plants grown under long daylength. b): Days after chilling treatment 

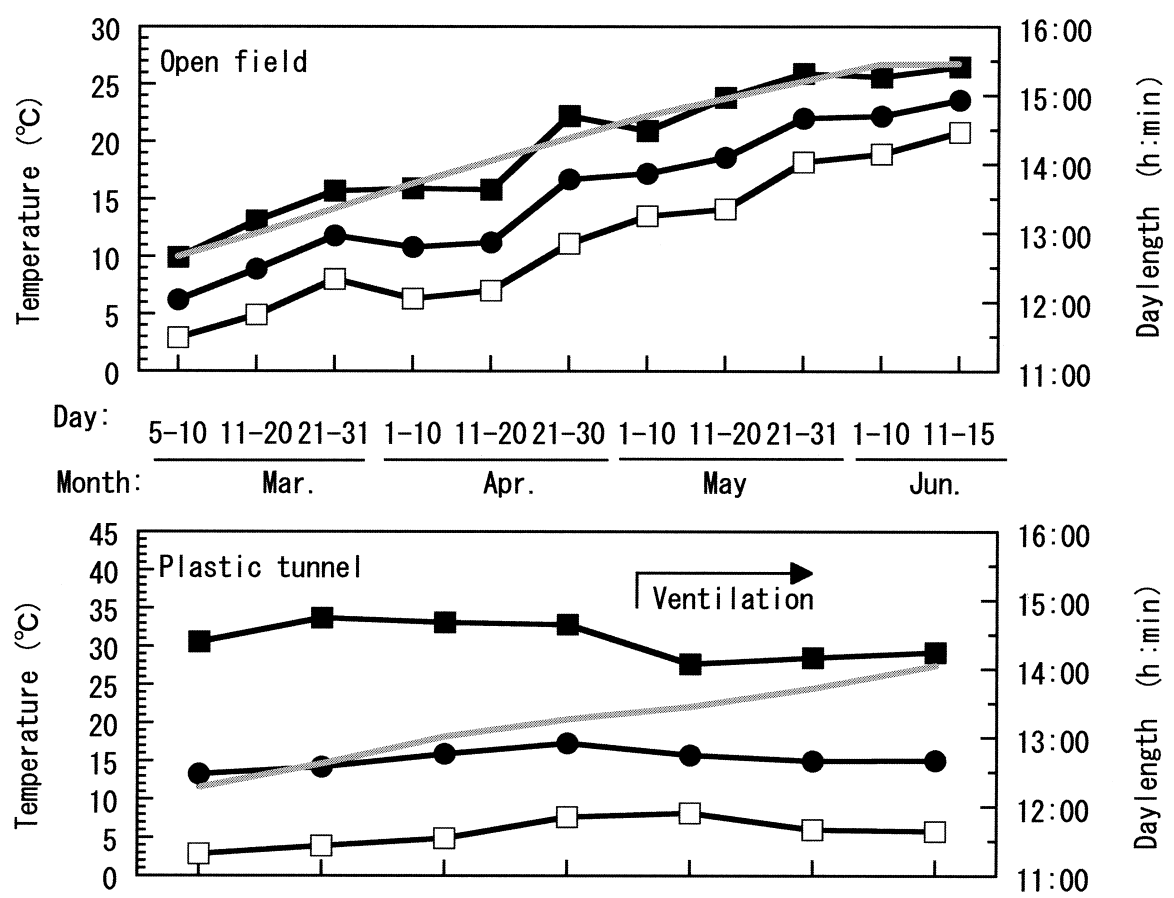

Day: $\frac{23-29}{\text { Menth: }} \frac{1-10 \quad 11-20 \quad 21-26 \quad 26-31}{\text { Mar. }} \frac{1-10 \quad 11-15}{\text { Apr. }}$

Fig. 4. Means of daily average $(O)$, minimum $(\square)$ and maximum $(\square)$ temperatures during the experiments shown in Fig. 1

Gray lines indicate natural daylength including 30 minutes of both dawn and dusk.
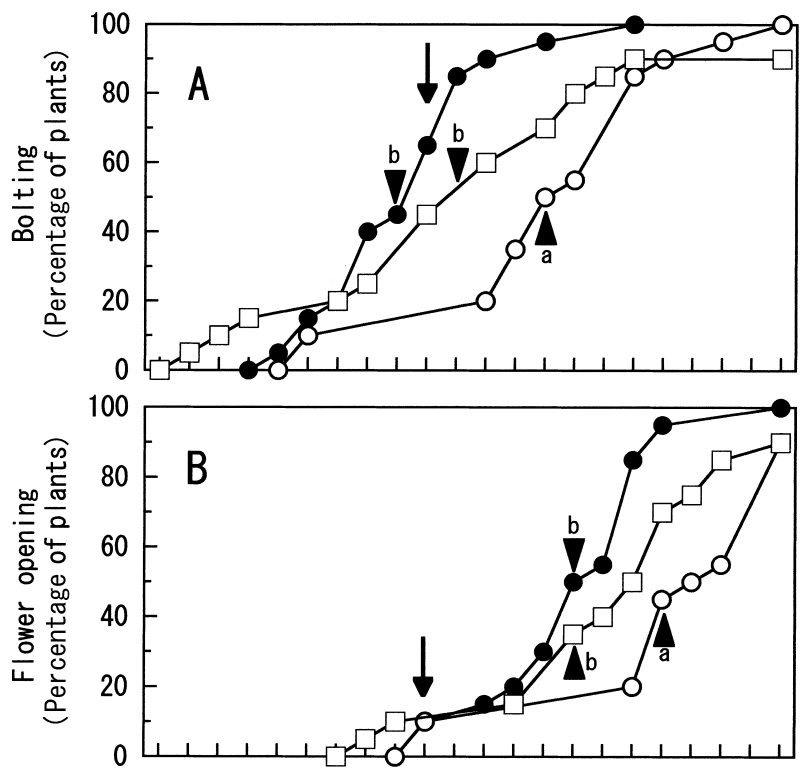

Day: 192123252729135791113151719212325272931

Month: Apr. May

Fig. 5. Bolting and flowering in cv. 'Taibyo-sobutori' planted on Feb. 23, 1996 and cultivated as shown in Fig. 1

A: bolting; time when the stem length reached a value of 5 $\mathrm{cm}$. B: flower opening. Symbols indicate the plants not treated with uniconazole $(\mathbf{)})$, the plants treated with uniconazole on Apr. $1(\bigcirc)$ and Apr. $11(\square)$. Solid triangles indicate averages, and the averages with the same letter are not significantly different at 5\% level. Arrows indicate harvest. zole is highly effective when the plants are not vernalized for long periods, and is applied before floral evocation. Since the effective concentration of uniconazole was 17 $\mu \mathrm{M}$ or higher, $17 \mu \mathrm{M}$ was adopted in the following field experiment.

\section{Effect of uniconazole treatment in winter and spring cultivation}

Temperature and daylength during cultivation are shown in Fig. 4. In cv. 'Taibyo-sobutori' planted on February 23, uniconazole treatment on April 11 did not affect bolting and flowering (Fig. 5). However, treatment on April 1 significantly retarded bolting and flowering. Bolting and flowering were delayed by 10 and 6 days, respectively, by uniconazole treatment. In contrast, uniconazole treatment was not effective in cv. 'Taibyo-sobutori' planted on April 5 (Fig. 6). In cv. 'Oshin' planted on March 5, uniconazole treatment on May 7 did not affect bolting and flowering (Fig. 7). However, treatment on April 27 delayed bolting and flowering by 7 and 5 days, respectively.

In the cases where uniconazole significantly retarded bolting and flowering, a substantial number of plants remained at the vegetative stage at the time of uniconazole treatment (see footnotes in Fig. 1). Most of the 

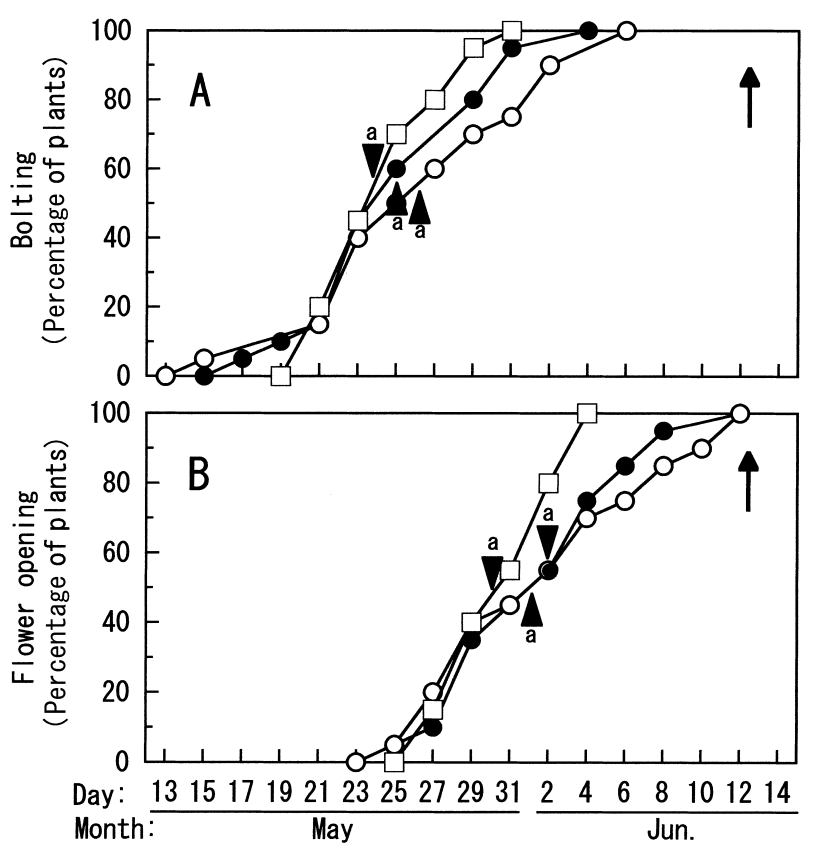

Fig. 6. Bolting and flowering in cv. 'Taibyo-sobutori' planted on Apr. 5, 1996 and cultivated as shown in Fig. 1

A: bolting; time when the stem length reached a value of $5 \mathrm{~cm}$. B: flower opening. Symbols indicate the plants not treated with uniconazole $(\mathbf{O})$, the plants treated with uniconazole on May 13 ( $\bigcirc$ ) and May $23(\square)$. Solid triangles indicate averages, and the averages with the same letter are not significantly different at $5 \%$ level. Arrows indicate harvest.
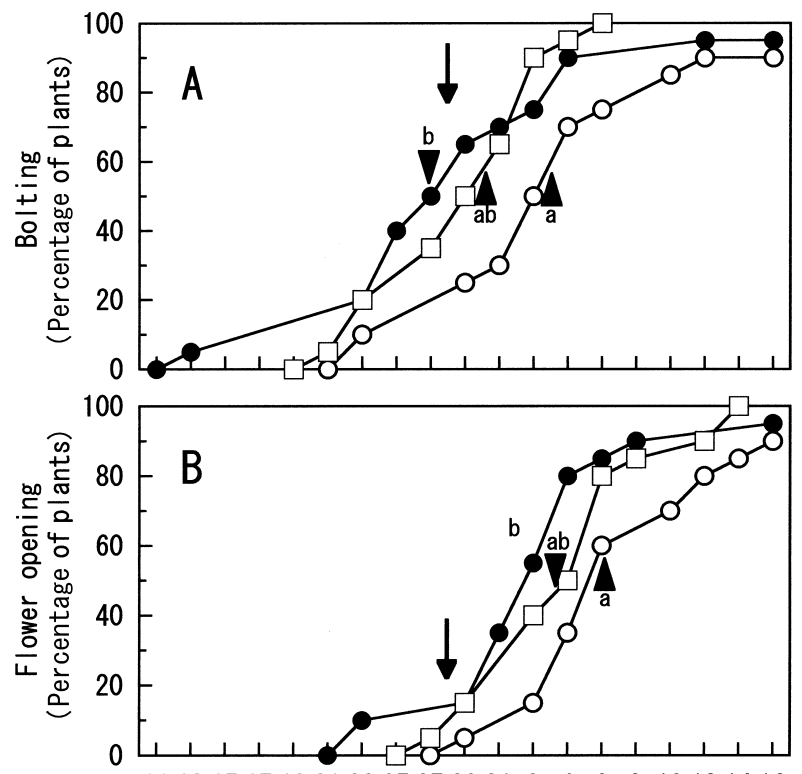

Day: $11131517192123252729312246 \quad 810121416$

Month: May Jun.

Fig. 7. Bolting and flowering in cv. 'Oshin' planted on Mar. 5, 1996 and cultivated as shown in Fig. 1

A: bolting; time when the stem length reached a value of $5 \mathrm{~cm}$. B: flower opening. Symbols indicate the plants not treated with uniconazole $(\bigcirc)$, the plants treated with uniconazole on Apr. $27(\bigcirc)$ and May $7(\square)$. Solid triangles indicate averages, and the averages with the same letter are not significantly different at $5 \%$ level. Arrows indicate harvest.

Table 2. Effect of uniconazole on growth of $R$. sativus cv. 'Taibyo-sobutori' and cv. 'Oshin' at harvest

\begin{tabular}{|c|c|c|c|c|c|c|c|c|}
\hline \multirow{2}{*}{$\begin{array}{l}\text { Cultivar } \\
\text { (Planting date) }\end{array}$} & \multirow{2}{*}{$\begin{array}{l}\text { Uniconazole } \\
\text { treatment }\end{array}$} & \multicolumn{4}{|c|}{ Shoot } & \multicolumn{3}{|c|}{ Taproot } \\
\hline & & $\begin{array}{l}\text { Stem length } \\
(\mathrm{cm})\end{array}$ & $\begin{array}{l}\text { Leaf length } \\
\qquad(\mathrm{cm})\end{array}$ & Leaf no. & $\begin{array}{l}\text { Stem longer } \\
\text { than } 10 \mathrm{~cm} \\
(\% \text { of plants })\end{array}$ & $\begin{array}{l}\text { Length } \\
(\mathrm{cm})\end{array}$ & $\begin{array}{l}\text { Diameter } \\
\quad(\mathrm{cm})\end{array}$ & $\begin{array}{c}\text { Fresh } \\
\text { weight }(g)\end{array}$ \\
\hline \multirow{3}{*}{$\begin{array}{l}\text { 'Taibyo-sobutori' } \\
\text { (Feb. 23) }\end{array}$} & Untreated & $13.4 \mathrm{a}$ & $49.1 \mathrm{a}$ & $34.5 \mathrm{~b}$ & 65 & $41.4 \mathrm{a}$ & $8.6 \mathrm{a}$ & $1,708 \mathrm{a}$ \\
\hline & Apr. 1 & $4.3 \mathrm{~b}$ & $46.7 \mathrm{~b}$ & $37.1 \mathrm{a}$ & 10 & $36.6 \mathrm{~b}$ & $8.8 \mathrm{a}$ & $1,489 \mathrm{a}$ \\
\hline & Apr. 11 & $11.9 \mathrm{a}$ & $45.7 \mathrm{~b}$ & $36.2 \mathrm{ab}$ & 35 & $36.2 \mathrm{~b}$ & $8.8 \mathrm{a}$ & $1,619 \mathrm{a}$ \\
\hline \multirow{3}{*}{$\begin{array}{l}\text { 'Taibyo-sobutori' } \\
\text { (Apr. 5) }\end{array}$} & Untreated & $99.6 \mathrm{a}$ & $47.7 \mathrm{a}$ & $35.9 \mathrm{a}$ & 100 & $32.3 \mathrm{a}$ & $6.5 \mathrm{a}$ & $751 \mathrm{a}$ \\
\hline & May 13 & $96.7 \mathrm{a}$ & $44.8 \mathrm{a}$ & $34.0 \mathrm{a}$ & 100 & $29.7 \mathrm{a}$ & $6.6 \mathrm{a}$ & 708 a \\
\hline & May 23 & 101.9 a & $44.9 \mathrm{a}$ & $31.9 \mathrm{a}$ & 100 & $31.3 \mathrm{a}$ & $6.5 \mathrm{a}$ & 739 a \\
\hline \multirow{3}{*}{$\begin{array}{l}\text { 'Oshin' } \\
\text { (Mar. 5) }\end{array}$} & Untreated & $18.0 \mathrm{a}$ & $45.0 \mathrm{a}$ & $42.8 \mathrm{ab}$ & 45 & $39.9 \mathrm{a}$ & $8.8 \mathrm{~b}$ & $1,736 \mathrm{a}$ \\
\hline & Apr. 27 & $4.3 \mathrm{~b}$ & $39.3 \mathrm{~b}$ & $44.4 \mathrm{a}$ & 10 & $37.6 \mathrm{a}$ & $9.6 \mathrm{a}$ & $1,821 \mathrm{a}$ \\
\hline & May 7 & $15.7 \mathrm{ab}$ & $37.4 \mathrm{~b}$ & $38.7 \mathrm{~b}$ & 40 & $39.1 \mathrm{a}$ & $9.6 \mathrm{a}$ & $1,861 \mathrm{a}$ \\
\hline
\end{tabular}

The plants were cultivated as shown in Fig. 1.

Averages followed by the same letter, in the same column, are not significantly different at $5 \%$ level. 
plants (92\%) of cv. 'Taibyo-sobutori' planted on February 23 were at the vegetative stage at the time of uniconazole treatment on April 1. About half of the plants (42\%) of cv. 'Oshin' planted on March 5 were also at the vegetative stage at the time of uniconazole treatment on April 27 . In contrast, most of the plants had reached the domeshaped stage at the time of uniconazole treatment when the chemical was ineffective in the retardation of bolting and flowering. A previous study had suggested that the concentration of endogenous gibberellin should be decreased before floral evocation to retard bolting and flowering effectively ${ }^{6}$. This assumption was confirmed in the present field experiment which simulates commercial production of Japanese radish.

Untreated plants of cv. 'Taibyo-sobutori' planted on February 23 and cv. 'Oshin' planted on March 5, showed conspicuous yield reduction due to bolting. This was because the taproots with flower stems longer than $10 \mathrm{~cm}$ were not included for yield calculation since they were considered commercially undesirable as food products. Percentage of these undesirable taproots was $65 \%$ in $\mathrm{cv}$. 'Taibyo-sobutori' planted on February 23 and $45 \%$ in cv. 'Oshin' planted on March 5 (Table 2). However, uniconazole treatment lowered the percentage of undesirable taproots to $10 \%$ in both cases. Since all the plants of cv. 'Taibyo-sobutori' planted on April 5 bolted and flowered before sufficient growth of the taproot was attained, commercially desirable taproots could not be harvested even when uniconazole was applied (Table 2).

In all of the above experiments, uniconazole was not harmful to taproot growth.

\section{Conclusion and perspective}

Chemical control of precocious bolting attempted previously using gibberellin biosynthesis inhibitor ${ }^{4,11}$ was not successful because the effect was unstable for unknown reasons. However, the present experiment suggested that this instability was due to inappropriate timing of treatment. Gibberellin biosynthesis inhibitor retards bolting and flowering only when it is applied before floral evocation (Figs. 2 and 3). Single application of uniconazole delayed bolting up to 10 days in the present field experiment (Figs. 5 and 7), which effectively reduced yield loss (Table 2). Because the taproot weight increases rapidly during the latter period of cultivation $^{2,8}$, this 10 -day delay in bolting is sufficient to prevent yield reduction in commercial production. It should be noted that the gibberellin biosynthesis inhibitor is ineffective when bolting and flower opening take place before rapid growth of the taproot (Fig. 6).

In the present experiment, only a single application of uniconazole at a certain concentration $(17 \mu \mathrm{M})$ was examined in the field experiment. However, it will be possible to enhance the effect of uniconazole if repeated applications or higher concentrations are employed. The experiment in the incubator supports this assumption (Figs. 2 and 3).

Winter and spring cultivation of Japanese radish was achieved by the combined use of slow-bolting cultivars and plastic films ${ }^{3,10}$. A double cover with film mulching and plastic tunnel is common in winter and spring cultivation. This double cover is sometimes further covered by a plastic house. It is preferable to decrease the use of plastic films for saving oil resources and reducing industrial waste. It is, however, necessary to avoid precocious bolting caused by low temperature. Furthermore, precocious bolting due to unusual weather conditions sometimes causes severe yield loss ${ }^{1}$. Thus, prevention of precocious bolting is an important aspect to be studied. Breeding slow-bolting cultivars is the optimum way to avoid precocious bolting. However, an emergency plan will be necessary to cope with unusual weather conditions. Furthermore, it will be necessary to enhance the slow-bolting trait for further reduction of use of plastic films. Chemical control should be a convenient and effective method for this purpose.

\section{References}

1. Katsura, N. \& Kunishige, M. (1989) Vegetables and ornamental plants, In Method of chemical regulation experiment in useful plants. ed. Takahashi, N., The Society for Chemical Regulation of Plant, Tokyo, 385-405 [In Japanese].

2. Kawai, T. \& Okuma, Y. (1970) Characteristics of growth phase in 'Minoyase' Japanese radish cultivated in Hiruzen district. Bull. Exp. Sta. Okayama Pref. 65, 98110.

3. Mogi, M. (1993) Spring culture of Japanese radish. In Systematic Encyclopedia of agricultural technology, Japanese radish, ed. Nobunkyo Co., Nobunkyo, Tokyo, 101130 [In Japanese].

4. Momma, S. (1988) Examination of growth regulation of vegetables, 1. Growth regulation of Japanese radish. In Research achievement 199, regulation of harvest time in open field vegetables and flowers, ed. Agriculture, Forestry and Fisheries Council Secretariat. Ministry of Agriculture, Forestry and Fisheries of Japan, Tokyo, 99-101 [In Japanese].

5. Nishijima, T. et al. (1997) Effects of uniconazole and GA on flowering and bolting of Raphanus sativus. Plant Growth Regul. 21, 207-214.

6. Nishijima, T. et al. (1998) Role of endogenous gibberellins in cold-induced stem elongation and flowering of Japanese radish (Raphanus sativus L.). J. Jpn. Soc. Hort. Sci. 67, 319-324.

7. Nishijima, T. et al. (1998) Effects of gibberellins and gib- 
berellin-biosynthesis inhibitors on stem elongation and flowering of Raphanus sativus L. J. Jpn. Soc. Hort. Sci. 67, 325-330.

8. Saito, K. (1934) Study on growth and development of 'Minoyase' Japanese radish. 1. Relationship between growth and temperature. Jpn. J. Crop Sci. 6, 173-183 [In Japanese].

9. Saito, T. (1983) Horticultural science of vegetables, legumes, root and leaf vegetables. Nobunkyo, Tokyo, 328-408 [In Japanese].
10. Seyama, N. \& Takai, T. (1982) Effect of day temperature on bolting of Japanese radish. Bulll. Natl. Res. Inst. Veg. Ornamental Plants Tea B, 4, 47-60.

11. Yamada, E. (1988) Retardation of flowering in vegetables. In Research achievement 199, regulation of harvest time in open field vegetables and flowers, ed. Agriculture, forestry and fisheries council secretariat. Ministry of Agriculture, Forestry and Fisheries of Japan, Tokyo, 90 92 [In Japanese]. 